\title{
Ferramentas digitais de gerenciamento da saúde da criança com microcefalia por
}

\section{Zika vírus: estudo de prospecção}

\author{
Digital health management tools for children with microcephaly by Zika virus: prospective study \\ Herramientas digitales de gestión de la salud para niños con microcefalia por virus Zika: estudio
} prospectivo

Geyse do Espírito Santo Rezende ORCID: https://orcid.org/0000-0002-2570-0543 Universidade Federal de Sergipe, Brasil E-mail: geyserezende@gmail.com

Vicente Jose Santiago Costa Oliveira ORCID: https://orcid.org/0000-0002-1097-7021 Universidade Federal de Sergipe, Brasil E-mail: vicentesantiago1603@gmail.com

Adicinéia Aparecida de Oliveira ORCID: https://orcid.org/0000-0002-1551-1992 Universidade Federal de Sergipe, Brasil E-mail: adicineia@gmail.com Lysandro Pinto Borges ORCID: https://orcid.org/0000-0002-1721-1547 Universidade Federal de Sergipe, Brasil E-mail: lysandro.borges@gmail.com

\begin{abstract}
Resumo
O presente artigo objetivou verificar a existência de aplicativos móveis que buscassem auxiliar crianças com microcefalia e seus cuidadores no gerenciamento e educação em saúde. Esta pesquisa tem caráter exploratório, quantitativo e qualitativo, de cunho bibliográfico, realizada em forma de prospecção científica e tecnológica em bases de depósitos de pedidos de patentes e registros de software, bases de dados científicos e lojas virtuais de aplicativos. Por meio das buscas, apenas 1 artigo foi selecionado para análise; trata-se de um aplicativo móvel de saúde voltado para cuidadores de crianças que tem a SKZv como uma ferramenta informativa para ajudar acompanhar o desenvolvimento dessas crianças. Estão dispostas no aplicativo funções para acompanhar o desenvolvimento da criança, acompanhamento das habilidades visuais e motoras, cadastro de consultas e função que possibilita a comunicação entre cuidadores e profissionais. A aplicação se mostrou muito promissora ao trazer informações a esse nicho de pessoas que tanto precisam, além de comprovar que um rápido diagnóstico e tratamento adequado são pontos-chave para a qualidade de vida das crianças. Por meio desse estudo de prospecção é possível afirmar que existem variados aplicativos voltados para os cuidados e desenvolvimento infantil, porém, é nítida a escassez de aplicativos voltados para o gerenciamento da saúde de crianças com microcefalia. Ao considerar o elevado número de crianças com microcefalia no Brasil, fica explícita a necessidade de ferramentas de saúde que possam auxiliar essa população.
\end{abstract}

Palavras-chave: Microcefalia; Cuidados de saúde; Saúde infantil; MHealth; Aplicativo de smartphone.

\begin{abstract}
This article aimed to verify the existence of mobile applications that seek to assist children with microcephaly and their caregivers in health management and education. This research has an exploratory, quantitative and qualitative, bibliographic nature, carried out in the form of scientific and technological prospecting in databases of patent applications and software registers, scientific databases and virtual stores of applications. Through the searches, only 1 article was selected for analysis; it is a mobile health app aimed at caregivers of children that has Skzv as an informative tool to help track the development of these children. Are arranged in the application functions to monitor the development of the child, monitoring of visual and motor skills, registration of appointments and function that enables communication between caregivers and professionals. The application proved to be very promising in bringing information to this niche of people who need it, in addition to proving that a rapid diagnosis and adequate treatment are key points for the quality of life of children. Through this prospecting study, it is possible to state that there are several applications aimed at child care and development, but the shortage of applications aimed at managing the health of children with microcephaly is clear. Considering the high number of children with microcephaly in Brazil, it is explicit the need for health tools that can help this population.
\end{abstract}


Keywords: Microcephaly; Health Care; Children's Health; Mhealth; Smartphone App.

\section{Resumen}

Este artículo tuvo como objetivo verificar la existencia de aplicaciones móviles que buscan a los niños con microcefalia y sus cuidadores en la gestión y educación en salud. Esta investigación es exploratoria, cuantitativa y cualitativa, de naturaleza bibliográfica, realizada en forma de prospección científica y tecnológica en bases de datos de presentación de solicitudes de patente y registros de software, bases de datos científicas y tiendas virtuales de aplicaciones. A través de las búsquedas, solo se seleccionó 1 artículo para su análisis; es una aplicación de salud móvil dirigida a los cuidadores de niños que tiene un SKZv como herramienta informativa para ayudar a rastrear el desarrollo de estos niños. La aplicación cuenta con funciones para monitorear el desarrollo del niño, monitoreo de habilidades visuales y motoras, registro de citas y una función que permite la comunicación entre cuidadores y profesionales. La aplicación es muy prometedora a la hora de acercar información a este nicho de personas que tanto la necesitan, además de demostrar que un diagnóstico rápido y un tratamiento adecuado son puntos para la calidad de vida de los niños. A través de este estudio de prospección, es posible afirmar que existen varias aplicaciones orientadas al cuidado y desarrollo infantil, sin embargo, existe una clara escasez de aplicaciones dirigidas al manejo de la salud de los niños con microcefalia. Al considerar el alto número de niños con microcefalia en Brasil, se hace evidente la necesidad de herramientas de salud para ayudar a esta población.

Palabras clave: Microcefalia; Cuidados de la Salud; Salud Infantil; Mhealth; Aplicación de Teléfono Inteligente.

\section{Introdução}

A população, dia após dia, aumenta o uso de tecnologia em sua rotina, em decorrência da latente necessidade de resolver situações com maior eficácia e menor gasto de tempo. $\mathrm{O}$ uso de aplicativos em smartphones abre um leque de possibilidades que vão desde à praticidade para realização de tarefas cotidianas até realizações de tarefas complexas; porém, para que o usuário tenha real interesse pelo aplicativo, é preciso que este se mostre útil, inovador ou beneficie o usuário de alguma forma (Guidini, 2018).

Inovação pode ser entendida como novas soluções tecnológicas, novos produtos ou serviços, ideias que visem a melhoria de serviços já existentes ou até mesmo a inserção de novos serviços em substituição a um anterior que não esteja mais sendo suficiente para a demanda (Maçães, 2017).

O aumento do uso de smartphones revelou um cenário propício para o desenvolvimento de ferramentas digitais, como os aplicativos móveis. $\mathrm{Na}$ área da saúde, aplicativos ganharam espaço no auxílio dos cuidados em saúde, pois, sendo sustentados por uma boa base científica, são capazes de gerar educação e promoção em saúde (Rezende, et al., 2020; Borges, et al., 2020; Sweileh, et al., 2017). A expansão dos cuidados clínicos ao ambiente familiar com o auxílio de aplicativos móveis, configura um novo modelo de medicina conhecido como mHealth, que busca ajudar os pacientes e profissionais da saúde no progresso do tratamento e melhorar os ganhos em saúde (Alonso-Arévalo \& Mirón-Canelo, 2017).

Dentre tantas patologias que necessitam de cuidados contínuos, destaca-se a Microcefalia, que é uma alteração da saúde na qual o bebê nasce com a cabeça menor que o esperado para a idade; esse termo médico é usado para se referir ao tamanho diminuído da cabeça, na qual o Perímetro Cefálico é menor em comparação a crianças da mesma idade e sexo (WHO, 2016). Essa má formação craniana pode ter origem multifatorial e é intimamente relacionada às infecções congênitas do grupo STORCH: Sífilis, Toxoplasmose, Rubéola, Citomegalovírus e Herpes simplex. O grupo de doenças STORCH, por sua vez, causa alterações neurológicas importantes, com anomalias do sistema nervoso central e microcefalia, semelhantemente à infecção pelo Zika Vírus (ZIKV) (Calheiros, et al., 2019).

Após o aumento anormal do número de casos de crianças com diagnóstico de microcefalia durante a epidemia causada pelo ZIKV em 2015 no Brasil, diversos pesquisadores se debruçaram sobre a temática e notaram que a microcefalia era mais uma das diversas consequências decorrentes da infecção. Dessa forma, o conjunto de características que essas crianças apresentaram denominou-se de Síndrome Congênita do Zika Vírus (SCZV) (Gulland, 2016; Massetti, et al., 2020; Santos, et al., 2020; Moraes, et al., 2016).

Ao se considerar os graves danos que a SCZV pode causar às crianças, é esperado que elas apresentem 
comprometimento neurológico importante como também dificuldades funcionais, o que demanda cuidados clínicos contínuo bem como dedicação familiar constante. Entretanto, o recebimento desse diagnóstico pode gerar um desequilíbrio em toda a harmonia familiar com a sobrecarga dos responsáveis que precisam se readaptar a aquela realidade, na qual, por diversas vezes se sentem impotentes e despreparados para lidar com os cuidados para aquela criança (Costa et al., 2018; Oliveira et al., 2018).

Nesse contexto, foi notado que aplicativos de cuidados e educação em saúde são ótimas ferramentas para que os cuidadores tenham maior conhecimento nos cuidados que estão sendo demandados aos filhos (Martins et al., 2018). Um aplicativo móvel desenvolvido como ambiente digital para acompanhamento da saúde das crianças com diagnóstico de microcefalia é eficaz na promoção do conhecimento e gerenciamento das atividades concernentes aos cuidados diários da criança (Borges, et al., 2021).

No âmbito da tecnologia e inovação, estudos de prospecção tecnológica são essenciais para detectar oportunidades de inovação que ajudem nas necessidades da sociedade, referentes à determinada problemática (Ribeiro e Alves, 2020). Desta forma, o presente artigo objetivou verificar a existência de aplicativos móveis que buscassem auxiliar crianças com microcefalia e seus cuidadores no gerenciamento e educação em saúde.

\section{Metodologia}

Esta pesquisa tem caráter exploratório, quantitativo e qualitativo, de cunho bibliográfico, realizada em forma de prospecção científica e tecnológica em bases de depósitos de pedidos de patentes e registros de software, bases de dados científicos e lojas virtuais de aplicativos.

Para a realização da prospecção científica foi feita uma busca, em forma de revisão sistemática, nas seguintes bases de dados: Scopus, IEEE Xplore, ScienceDirect, Web of Science, Engineering Village, Periódico CAPES e Google Acadêmico. O acesso aos artigos completos dessas bases foi possível pelo portal de periódicos da CAPES, mediante ao acesso CAFe (Comunidade Acadêmica Federada).

Já na realização da prospecção tecnológica, foi feita uma busca nas bases de depósitos de pedidos de patentes e registros de software: base do Instituto Nacional da Propriedade Industrial (INPI), WIPO - OMPI (PATENTSCOPE), EPO SPACENET e Google Patents. As buscas no INPI foram realizadas objetivando o RPC - Registro de Programa de Computador; já nas demais bases de patente, que as buscas foram direcionadas às patentes de processo que possam ter gerados produtos de software relacionados.

Também foi necessário realizar buscas mercadológicas nas duas principais lojas de aplicativos móveis do sistema Android e IOS: Play Store e App Store. A busca foi realizada de forma manual, sem utilização de software para auxílio. A Figura 1 apresenta o organograma das bases de dados utilizadas.

Para melhor compreensão, a metodologia está subdividida de acordo com os tipos de prospecção realizadas no decorrer da pesquisa. 
Figura 1 - Organograma das bases utilizadas nas prospecções.

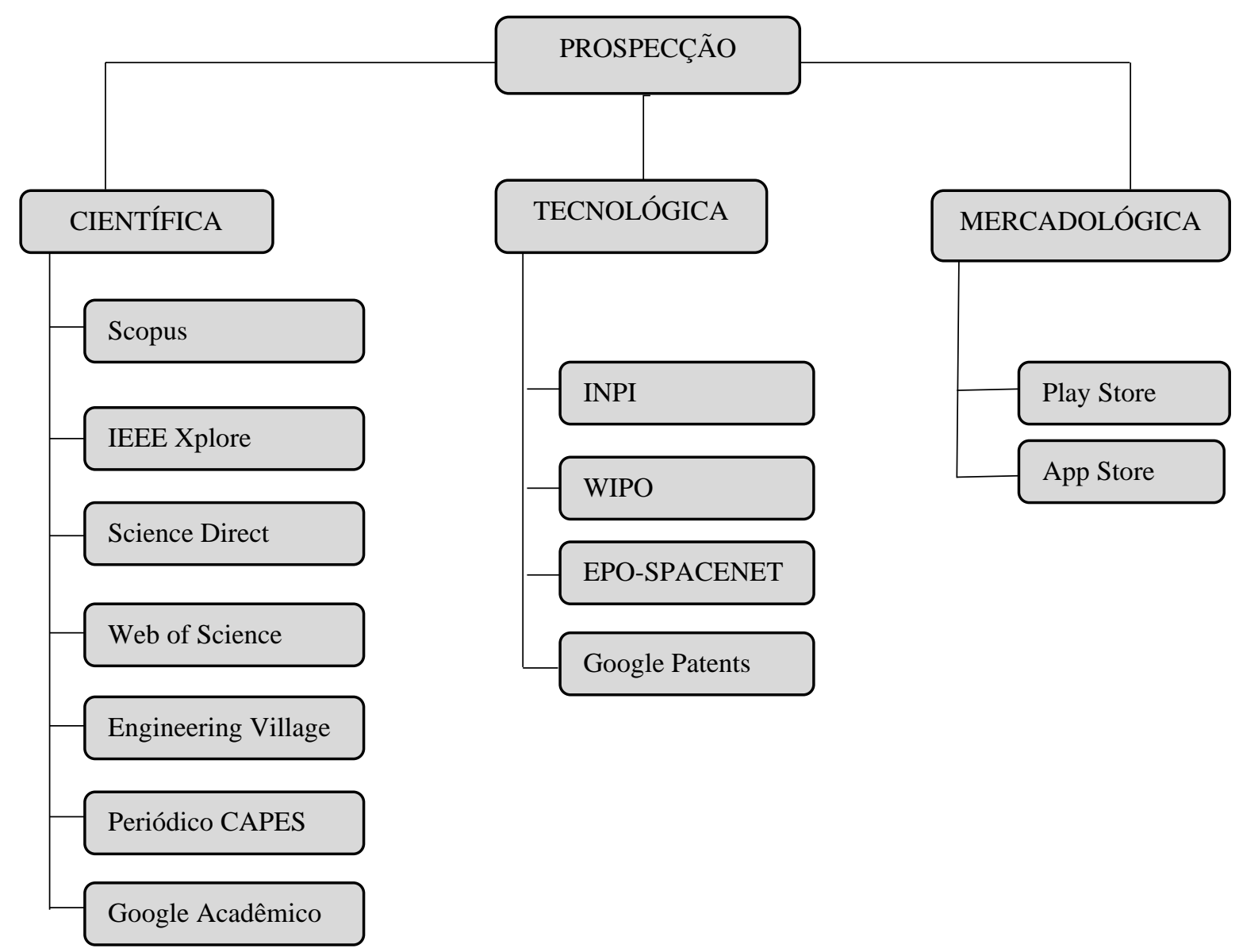

Fonte: Autores (2021).

\subsection{Revisão Sistemática}

O processo de Revisão Sistemática contou com a colaboração da ferramenta StArt 6 (versão 2.3.4.2), um software que auxilia o método de Revisão Sistemática. Segundo Cerrao, Jesus e Castro (2019), o software StArt é uma ótima ferramenta computacional capaz de dar maior qualidade e facilitar a realização da Revisão Sistemática. Este software é composto por 3 módulos principais: planejamento, que inclui o protocolo de busca; execução, que inclui as etapas de inclusão e seleção dos estudos, bem como a etapa de extração de dados; sumarização, onde são registrados os resultados finais da revisão sistemática.

Assim sendo, foi objetivado selecionar os principais trabalhos e responder as seguintes questões:

- Quais são as principais aplicações desenvolvidas e publicadas para atender o público com microcefalia?

- Quais são os tipos de funcionalidades disponíveis nessas aplicações?

- Quais são os públicos alvos dessas soluções (cuidadores ou crianças)?

Posteriormente, foi feito o preenchimento do protocolo, o qual é composto por 18 campos que embasam o processo de busca, seleção e extração dedados. Dentre esses 18 campos, cabe destacar 04, os quais foram essenciais para o processo, sendo eles:

- Bases de dados consultadas;

- Palavras-chave utilizadas nas buscas;

- Critérios de inclusão e exclusão de artigos;

- Informações extraídas dos artigos escolhidos. 
A busca nas bases selecionadas foi realizada em dezembro de 2020 e foi feito o upload dos artigos encontrados em formato .bib para a referida ferramenta.

Para realizar a pesquisa nas bases selecionadas foram considerados apenas os trabalhos publicados nos últimos cinco anos (2016-2020), escritos no idioma inglês ou português, relacionados à temática deste trabalho e que apresentam um conjunto de palavras-chave que tenham afinidade com o tema da pesquisa; além dos critérios elencados anteriormente, também foram considerados apenas artigos que se tratassem de uma proposta de solução mobile no suporte à saúde da criança com microcefalia e que estivessem disponíveis para leitura de forma gratuita e completa. Desta forma, foram selecionadas as palavras-chave: Aplicativo móvel, Saúde infantil, Zika Vírus, microcefalia, Síndrome Congênita do Zika Vírus e suas versões em inglês, como mostra o Quadro 1.

Quadro 1 - Palavras-chave.

\begin{tabular}{|l|l|}
\hline Palavra-Chave & Termos (Inglês) \\
\hline Microcefalia & Microcephaly \\
\hline Cuidados de saúde & Health care \\
\hline Saúde infantil & Children's health \\
\hline Cuidadores de crianças & Child Caregivers \\
\hline MHealth & MHealth \\
\hline Móvel & Mobile \\
\hline Aplicativo de smartphone & Smartphone app \\
\hline
\end{tabular}

Fonte: Autores (2021).

Além da definição das palavras-chave também foi necessário gerar strings de busca genéricas para realizar as pesquisas nas bases selecionadas. A string é exibida no Quadro 2. Com a organização das palavras-chave, derivou-se a seguinte string de busca:

- Português: (“Aplicativo móvel” OU “aplicativo para smartphone” OU “saúde móvel”) E (“saúde” OU “saúde infantil”) E (“microcefalia” OU “Síndrome congênita do zika vírus”).

- Inglês: ("Mobile app" OR “smartphone app" OR “mobile health") AND ("health" OR “child health") AND ("microcephaly" OR "Zika Virus Congenital Syndrome").

Quadro 2 - Strings de busca genérica.

\begin{tabular}{|l|}
\hline String Genérica \\
\hline (“mobile application" OR “smartphone app" OR “mhealth”) AND \\
("healthcare” OR “children's health") AND (“microcephaly”) \\
\hline
\end{tabular}

Fonte: Autores (2021).

O objetivo dessa string é servir como modelo para a pesquisa de forma mais consistente nas diferentes bases, e assim garantir um resultado correto. A partir da string genérica foram criadas string específicas para sustentar a busca nas diferentes fontes, respeitando suas particularidades e formatações.

Para manter a compatibilidade dos artigos selecionados foram definidos critérios de inclusão e exclusão, a fim de filtrar os estudos mais coerentes com o tema e retirar os que estavam incompletos, indisponíveis ou que não atendiam ao escopo definido.

Como critérios de inclusão foram definidos:

- O artigo deve propor o uso de uma aplicação para dispositivos móveis no cuidado da saúde da criança com microcefalia; 
- O artigo deve abordar modelos de arquitetura mobile para cuidados com a saúde;

- O artigo deve propor modelos ou técnicas para o desenvolvimento de tecnologia mobile voltada para a saúde infantil;

- $\quad$ O artigo deve propor o uso de soluções mobile no suporte à saúde da criança com microcefalia;

- O artigo encontra-se disponível no idioma inglês ou português;

- O artigo deve ser acessível e completo.

Sobre os critérios de exclusão, estão listados:

- $\quad$ O artigo propõe uma tecnologia não aplicável em smartphones;

- O artigo não descreve o uso de um sistema computacional;

- O artigo não apresenta uma solução mobile aplicada à saúde da criança com microcefalia;

- O artigo não apresenta uma solução voltada para os cuidadores/responsáveis por crianças;

- O artigo é um livro ou parte de um livro;

- O artigo não relaciona tecnologia com saúde;

- O artigo não está completo, está indisponível na internet ou está duplicado.

Após a aplicação dos critérios de inclusão e exclusão foi observado que dentre os artigos encontrados 8 estavam duplicados. Além disso, após a leitura dos títulos e de seus resumos foi observado que 29 desses artigos apresentavam ao menos um dos critérios de exclusão. Totalizando 21 artigos aceitos para a para análise e leitura completa. Para serem considerados aceitos, os artigos precisavam atender a um ou mais critérios de inclusão previamente definidos. Nessa análise foi observado que todos os documentos se encontravam escritos no idioma inglês, apresentavam uma abordagem similar com o tema proposto e estavam com acesso livre. A mesma análise foi feita para os critérios de exclusão, levando em conta a discrepância com o tema, falta de tecnologias sugeridas em estudo e por não estar disponível integralmente na internet, reforçando a ideia de que os artigos podem ter sido excluídos por apresentar um ou mais critérios.

Na fase de extração, uma leitura mais profunda dos trabalhos foi realizada, a fim de apurar o conteúdo do trabalho e filtrar ainda mais os resultados, levando em conta novamente os critérios já definidos. Após a leitura completa dos artigos aceitos na etapa de extração, foi feito um resumo sobre cada artigo selecionado.

\subsection{Prospecção Tecnológica}

Para a realização da prospecção tecnológica nas bases de depósitos de pedidos de patentes e registros de software, foram utilizadas as seguintes palavras-chave:

- Microcefalia;

- Microcephaly;

- Zika Vírus;

- Crescimento infantil;

- Desenvolvimento infantil

- MHealth;

- Móvel;

- Aplicativo de smartphone.

Foram selecionados para análise posterior apenas os resultados que estivessem compatíveis com o objetivo proposto na pesquisa. 


\subsection{Prospecção Mercadológica}

Com relação à busca realizada nas duas principais lojas de aplicativos móveis do sistema Android e IOS, foram utilizadas as seguintes palavras-chave:

- Microcefalia;

- Microcephaly;

- Zika Vírus;

- Crescimento infantil;

- Desenvolvimento infantil.

Na busca, foram seguidos os seguintes critérios:

- Aplicativo de uso gratuito;

- Avaliação geral acima de 4 estrelas;

- Acima de 1000 downloads;

- Encontrado dentro da categoria Aplicativo;

- Idioma Português (BR).

Do mesmo modo, foram selecionados para análise posterior, apenas os resultados que estivessem compatíveis com o objetivo proposto na pesquisa.

\section{Resultados}

\subsection{Prospecção Científica}

$\mathrm{Na}$ busca realizada nas bases científicas, foram encontrados 347 trabalhos. Após a aplicação dos critérios de inclusão e exclusão foi observado que dentre os artigos encontrados 8 estavam duplicados. Além disso, após a leitura dos títulos e de seus resumos, foi observado que 346 desses artigos apresentavam ao menos um dos critérios de exclusão. Assim sendo, apenas 1 artigo foi aceito para análise e leitura completa, ou seja, apenas 1 artigo apresentou um aplicativo que teve por objetivo o gerenciamento da saúde de crianças com microcefalia, como pode ser visto na Tabela 1.

Tabela 1- Resultados da Revisão sistemática.

\begin{tabular}{llll}
\hline Base/Loja & Resultados encontrados & Excluídos após aplicação dos critérios & Selecionados para análise \\
\hline Scopus & 10 & 9 & 1 \\
IEEE Xplore & 1 & 1 & 0 \\
Science Direct & 6 & 6 & 0 \\
Web of Science & 33 & 6 & 0 \\
Engineering Village & 7 & 7 & 0 \\
Periódico CAPES & 7 & 7 & 0 \\
Google Acadêmico & 283 & 283 & 0 \\
\hline TOTAL & 347 & 346 & 1 \\
\hline
\end{tabular}

Fonte: Autores (2021).

$\mathrm{O}$ artigo resultante da pesquisa tem por título: ZCare: Designing a mobile application to support caregivers of patients with congenital zika syndrome (Kalantari e Motti, 2018). O mesmo discorre sobre a problemática da microcefalia no Brasil e 
traz para um contexto no qual os cuidadores de crianças não possuem condições favoráveis para arcar com custos e terapias. Nesse cenário o artigo propõe o uso de um aplicativo para os cuidadores dessas crianças, através do qual é possível se manter informado e realizar diversas atividades.

No escopo do estudo nos é apresentada uma hierarquia completa de tarefas que podem ser realizadas por meio do aplicativo, dentre elas:

- Cadastro de consultas;

- Acompanhamento do desenvolvimento da criança;

- Um meio de interação com outros cuidadores e profissionais;

- Sessão de informações visuais com fotos e vídeos;

- Checagem das habilidades motoras e visuais da criança.

O ZCare é um aplicativo móvel de saúde voltado para cuidadores de crianças que tem a SKZv como uma ferramenta informativa para ajudar acompanhar o desenvolvimento dessas crianças. Estão dispostas no aplicativo funções para acompanhar o desenvolvimento da criança, acompanhamento das habilidades visuais e motoras, cadastro de consultas e função que possibilita a comunicação entre cuidadores e profissionais. A aplicação se mostrou muito promissora ao trazer informações a esse nicho de pessoas que tanto precisam, além de comprovar que um rápido diagnóstico e tratamento adequado são pontoschave para a qualidade de vida das crianças.

\subsection{Prospecção Tecnológica}

$\mathrm{Na}$ base do Instituto Nacional da Propriedade Industrial (INPI), na aba de registro de Programa de Computador, a busca retornou 16 resultados, porém, apenas com a leitura dos títulos, não foi possível identificar algum aplicativo ou software que fosse relacionado ao objetivo da pesquisa. Cabe ressaltar que não é possível verificar a especificidade do software, devido à limitação da publicidade do mesmo.

Na busca feita no WIPO - OMPI (PATENTSCOPE), retornaram 6 resultados com o uso das palavras-chave, porém, a partir da leitura dos títulos foi possível notar que não havia nenhuma proximidade com o objetivo da busca deste trabalho.

A busca realizada na EPO - SPACENET exibiu 37 patentes, entretanto, nenhuma delas se tratava de uma ferramenta de gerenciamento da saúde de crianças com microcefalia por ZIKV.

Já na busca feita no Google Patents foram encontradas 7 patentes, porém, todas eram referentes a métodos de tratamento e não aplicativos de cuidados em saúde de crianças com microcefalia.

\subsection{Prospecção Mercadológica}

Após serem aplicados os critérios elencados, foram encontrados aplicativos voltados para saúde e desenvolvimento infantil, porém, nenhum desses disponibilizava orientações específicas para crianças com microcefalia. Mesmo não se tratando de uma busca robusta, com viés científico, foram utilizadas algumas das palavras-chave do protocolo de busca, através das quais foi possível perceber a escassez de aplicativos voltados para o tema de estudo.

$\mathrm{Na}$ busca realizada na Play Store, retornaram 7 resultados referentes a aplicativos voltados para cuidados infantis, porém, nenhum deles é voltado exclusivamente para o público com microcefalia.

Já na busca realizada na App Store, apenas 2 aplicativos se tratavam de ferramentas para gerenciamento da saúde infantil, no entanto, também não se tratavam de aplicativos voltados para a saúde de crianças com microcefalia. 


\section{Discussão}

A partir dos resultados obtidos, foi visto que apenas 1 aplicativo de acordo com os objetivos foi encontrado. A ausência de publicação científica sobre outros aplicativos voltados para o este público pode ser justificada pela necessidade de os autores resguardarem o sigilo e confidencialidade sobre as informações referentes a uma nova tecnologia. De acordo com a Lei $\mathrm{n}^{\circ}$ 9.609, de 19 de fevereiro de 1998, torna-se necessário manter em sigilo quaisquer dados que sejam considerados suficientes para identificar e caracterizar originalidade da inovação tecnológica, o qual pode ser divulgado após o devido registro.

A criação do aplicativo ZCare, destacado nesta pesquisa, foi motivada pelo fato de que cuidadores de crianças com microcefalia apresentam condições financeiras precárias para custear o acompanhamento da saúde da criança. Recentemente, Rezende e colaboradores (2020) realizaram um estudo com a população composta por cuidadores de crianças com microcefalia e evidenciaram que mais da metade da população investigada é composta por mulheres, as quais vivem com uma renda equivalente a um salário mínimo. Segundo um levantamento realizado pelo Ministério da Cidadania, cerca de 3.112 crianças nascidas com microcefalia de janeiro de 2015 a dezembro de 2018, recebem o Benefício de Prestação Continuada (BPC) no valor de um salário mínimo (Pereira, et al., 2017; Agência Senado, 2020). Esses dados ratificam a necessidade levantada por Kalantari e Motti (2018), os quais destacaram a necessidade dessa população em receber auxílio nos cuidados dessas crianças.

Segundo o último boletim epidemiológico emitido em 2020, de 2015 até 2020, no Brasil, receberam a confirmação diagnóstica o total de 3.535 casos de crianças com a Síndrome Congênita do Zika Vírus (BRASIL, 2020). Ao considerar esse cenário, no qual é nítido o crescente número de pessoas que apresentam alterações neurológicas, Pereira et al., (2021) destacou a importância da existência de recursos terapêuticos que auxiliem essa população.

Ferramentas tecnológicas, como aplicativos móveis, trazem grandes benefícios ao usuário e as mesmas têm potencial para difundir informações com base científica (Oliveira e Alencar 2017; Amorim et al., 2018; Diniz et al., 2019; Silva et al., 2019). O uso de aplicativos mobile gera adequações no comportamento ou até mesmo mudanças na rotina, o que leva, consequentemente, a uma melhora na saúde, sendo este uma ótima ferramenta na promoção da saúde (Delgado, et al., 2017). No entanto, é imprescindível que os aplicativos disponibilizados para uso tenham embasamento científico, de modo a repassar informações científicas de qualidade de forma confiável, pois o mau uso pode ocasionar prejuízos à saúde do usuário (Borges, Santos e Invenção, 2020).

Apesar das prospecções tecnológicas e mercadológicas não terem retornado nenhum resultado que fosse compatível com o objetivo desta pesquisa, existe uma expectativa de que a área da saúde passe por avanço tecnológico e que novas ferramentas de auxílio sejam desenvolvidas. De acordo com o estudo realizado por Moura, Pitta \& Tonholo (2020), com a pandemia do novo coronavírus, era esperado que ocorressem modificações na área da assistência em saúde, de modo que ferramentas tecnológicas ganhassem importância nos cuidados em saúde; a expectativa é que, nos próximos anos, a tecnologia avance muito mais na área da saúde e seja melhor aproveitada.

\section{Considerações Finais}

Por meio desse estudo de prospecção é possível afirmar que existem variados aplicativos voltados para os cuidados e desenvolvimento infantil, porém, é nítida a escassez de aplicativos voltados para o gerenciamento da saúde de crianças com microcefalia. Ao considerar o elevado número de crianças com microcefalia no Brasil, fica explícita a necessidade de ferramentas de saúde que possam auxiliar essa população. 
É possível que não existam muitas publicações difundindo a criação de aplicativos móveis voltados para essa população devido à necessidade de resguardar o sigilo referente a um possível aplicativo ainda não registrado, porém, esperase que essa realidade mude em benefício dessas crianças.

A realização de prospecção tecnológica é imprescindível para que sejam encontradas oportunidades de desenvolvimento tecnológico voltadas para áreas pouco visadas, mas que necessitam de investimento. Diante dessa realidade, espera-se que novos estudos de prospecção sejam realizados com a finalidade de destacar lacunas para assim serem desenvolvidas novas ferramentas tecnológicas.

\section{Referências}

Agência Senado. Sancionada lei que garante pensão vitalícia a crianças atingidas por Zika vírus. Abr, 2020. Disponível em: https://www12.senado.leg.br/noticias/materias/2020/04/08/sancionada-lei-que-garante-pensao-vitalicia-a-criancas-atingidas-por-zika-virus Acessado em $28 / 04 / 2021$

Alonso-Arévalo, Julio, \& Mirón-Canelo, José Antonio. (2017). Aplicaciones móviles en salud: potencial, normativa de seguridad y regulación. Revista Cubana de Información en Ciencias de la Salud, 28(3).

Amorim, D. N. P., Sampaio, L. V. P., Carvalho, G. d. A., \& Vilaça, K. H. C. (2018). Aplicativos móveis para a saúde e o cuidado de idosos. Revista Eletrônica de Comunicação, Informação e Inovação em Saúde, 12(1). https://doi.org/10.29397/reciis.v12i1.1365

Borges, L.P., Rezende, G.E.S., Oliveira, A.A., Oliveira, V.J.S.C. (2021). Micronews: mobile application to support children with microcephaly. Journal of Applied Biotechnology and Bioengineering; 8(5):131-137.

Borges, L.P., Santos, K.A., Invenção, G.B. (2020) Tecnologia aplicada a saúde: Aplicativos Fake, compreendemos o risco? In: de Cassia Silva, S. (Ed.). (2020). Gestão e Inovação Tecnológica em Saúde. Backup Books Editora. https://doi.org/10.47022/backup.books016

BRASIL. Lei no 9.609, de 19 de fevereiro de 1998. Dispõe sobre a proteção da propriedade intelectual de programa de computador, sua comercialização no País. Disponível em:www.planalto.gov.br. Acesso em 12 de outubro de 2021.

BRASIL. Ministério da Saúde. Secretaria de Vigilância Epidemiológica. Monitoramento dos casos de arboviroses urbanas transmitidas pelo Aedes Aegypti (dengue, chikungunya e zika), Semanas Epidemiológicas 1 a 26, 2020. Boletim Epidemiológico, vol. 51; n. 28 , Jul, 2020.

Calheiros, M.; Trevisan, C.; Siebra, S.; Pinto, J. ORG. (2019) Atenção à criança: atenção integral às crianças com alterações do crescimento e desenvolvimento relacionadas às infecções Zika e Storch - Recife: Instituto Aggeu Magalhães.

Cerrao, N. G., Jesus, A. F. de, \& Castro, F. F. de. (2019). O método de Revisão Sistemática da Literatura (RS) na área da Ciência da Informação no Brasil: análise de dados de pesquisa. Informação \& Tecnologia, 5(1), 105-116. https://doi.org/10.22478/ufpb.2358-3908.2018v5n1.38083

Costa, E. d. S., Bonfim, E. G., Magalhães, R. d. L. B., \& Viana, L. M. M. (2018). Mothers' experiences of children with microcephaly. Revista da Rede de Enfermagem do Nordeste, Artigo e3453. https://doi.org/10.15253/2175-6783.2018193453

Delgado M, Miranda S, Rodrigues PF. Uma avaliação das aplicações mobile classificadas em saúde e fitness. Acta Port Nutr 2017; 8:22-26.

Diniz, C. M. M., Leal, L. P., Guedes, T. G., Linhares, F. M. P., \& Pontes, C. M. (2019). Contribuições dos aplicativos móveis para a prática do aleitamento materno: revisão integrativa. Acta Paulista de Enfermagem, 32(5), 571-577. https://doi.org/10.1590/1982-0194201900079

Guidini, P. (2018). A comunicação com o mercado por meio de aplicativos: desafios e oportunidades. Signos do Consumo, 10(1), 59. https://doi.org/10.11606/issn.1984-5057.v10i1p59-69

Gulland, A. (2016). Zika virus may be linked to several birth defects, expert warns. BMJ, i1322. https://doi.org/10.1136/bmj.i1322

Kalantari, N., Motti, V.G. "zCare: Designing a Mobile Application to Support Caregivers of Patients with Congenital Zika Syndrome," 2018 IEEE International Conference on Healthcare Informatics (ICHI), 2018, pp. 276-283, doi: 10.1109/ICHI.2018.00038.

Maçães, M. R. (2017). Empreendedorismo, Inovação e Mudança Organizacional (Vol. III). Coimbra: Conjuntura acutal.

Martins, P. L., Azevedo, C. d. S., \& Afonso, S. B. C. (2018). O papel da família nos planos de tratamento e no cuidado pediátrico hospitalar em condições crônicas complexas de saúde. Saúde e Sociedade, 27(4), 1218-1229. https://doi.org/10.1590/s0104-12902018170402

Massetti, T., Herrero, D., Alencar, J., Silva, T., Moriyama, C., Gehrke, F., Tonks, J., Fonseca, F., Watson, S., Monteiro, C., \& Voos, M. (2020). Clinical characteristics of children with congenital Zika syndrome: a case series. Arquivos de Neuro-Psiquiatria, 78(7), 403-411. https://doi.org/10.1590/0004$282 \times 20200020$

Moraes, M., Sobrero, H., Mayans, E., Borbonet, D. (2016). Infección por virus Zika en el embarazo y el recién nacido. Archivos de Pediatría del Uruguay, 87(4), 374-383. 
Research, Society and Development, v. 10, n. 4, e389101321336, 2021

(CC BY 4.0) | ISSN 2525-3409 | DOI: http://dx.doi.org/10.33448/rsd-v10i13.21336

Moura, F. R. E., Pitta, G. B. B., \& Tonholo, J. (2020). Prospecção tecnológica de internet das coisas no contexto dos hospitais inteligentes. Research, Society and Development, 9(11), Artigo e50791110081. https://doi.org/10.33448/rsd-v9i11.10081

Oliveira, A. R. F., Alencar, M. S. M. (2017). O uso de aplicativos de saúde para dispositivos móveis como fontes de informação e educação em saúde. RDBCI: Revista Digital de Biblioteconomia e Ciência da Informação, 15(1), 234. https://doi.org/10.20396/rdbci.v0i0.8648137

Oliveira, M. C., Moreira, R. D. C. R., Lima, M. M., \& Melo, R. O. (2018). VIVÊNCIAS DE MÃES QUE TIVERAM FILHOS COM MICROCEFALIA. Revista Baiana de Enfermagem32, . https://doi.org/10.18471/rbe.v32.26350

Pereira, T. M. A., Siqueira, J. I. d. B., Nascimento, L. d. S., Almeida, C. C., Orsini, M., Silva, J. d. M., Rocha, J. A., \& Bastos, V. H. d. V. (2021). Prospecção científica e tecnológica do uso da vibração focal em comprometimentos motores em decorrência de patologias neurológicas. Research, Society and Development, 10(5), Artigo e13310514736. https://doi.org/10.33448/rsd-v10i5.14736

Rezende, G.E.S., Borges, L.P., Oliveira, A.A., Oliveira, V.J.S.C. (2020) MicroNEWS: Perfil tecnológico dos usuários e desenvolvimento do aplicativo móvel de suporte à criança com microcefalia. In: de Cassia Silva, S. (Ed.). (2020). Gestão e Inovação Tecnológica em Saúde. Backup Books Editora. https://doi.org/10.47022/backup.books016

Ribeiro, M. do C. O., \& Alves, F. M. M. (2020). Estudo de prospecção da produção científica e tecnológica do SARS-CoV-2. Revista Fontes Documentais, 3, $572-582$

Santos, G. P. G., Gouveia, M. T. d. O., Costa, R. M. P. G., Santos, A. M. R. d., \& Avelino, F. V. S. D. (2020). Effects in the development of children exposed to zika virus in the fetal period: an integrative review. Revista Brasileira de Enfermagem, 73(suppl 4). https://doi.org/10.1590/0034-7167-2019-0883

Silva, R. M. d., Brasil, C. C. P., Bezerra, I. C., \& Queiroz, F. F. d. S. N. (2019). Mobile health technology for gestational care: evaluation of the GestAção's app. Revista Brasileira de Enfermagem, 72(suppl 3), 266-273. https://doi.org/10.1590/0034-7167-2018-0641

Sweileh, W. M., Al-Jabi, S. W., AbuTaha, A. S., Zyoud, S. H., Anayah, F. M. A., \& Sawalha, A. F. (2017). Bibliometric analysis of worldwide scientific literature in mobile - health: 2006-2016. BMC Medical Informatics and Decision Making, 17(1). https://doi.org/10.1186/s12911-017-0476-7

WHO. (2016). Screening, assessment and management of neonates and infants with complications associated with Zika virus exposure in útero. Genebra: World Health Organization. 